\title{
REVISITANDO CONCEITOS: A ESTRUTURA SOCIAL DOS PESCADORES-COLETORES PRÉ-COLONIAIS *
}

\author{
Márcia Barbosa da Costa Guimarães**
}

\begin{abstract}
"The anthropologists took this primitive society as their special subject, but in practice primitive society proved to be their own society (as they understood it) seen in a distorting mirror. For them modern society was defined above all by the territorial state, the monogamous family and private property. Primitive society therefore must have been nomadic, ordered by blood ties, sexuality promiscuous and communist" (Kuper 1988:5).
\end{abstract}

Um conceito-chave incorporado à Arqueologia brasileira nas abordagens aos grupos construtores de sambaquis relaciona-se à teoria da sociedade primitiva, particularmente à concepção de bando, consubstanciada no seu vetor espaço/temporal, o nomadismo.

O uso do conceito de bando ${ }^{1}$ na arqueologia de sambaquis teve por base a efervescência acadêmica que agitava a antropologia americana nos anos 40 e 50 em torno da tentativa de descobrir princípios ou "leis" de desenvolvimento cultural e social e que envolviam diretamente a tão persistente e renovada teoria sobre sociedade primitiva.

Como observa Kuper (1988), a história convencional da Antropologia descreve uma sucessão de teorias - evolucionismo, difusionismo, funcionalismo, estruturalismo etc.. Contudo, essas tradições teóricas se voltaram para a mesma idéia de sociedade primitiva, pois tinham como objeto referencial sua própria sociedade.

(*) Este estudo é parte integrante da dissertação de mestrado "O Espaço e a Organização Social do Grupo Construtor do Sambaqui IBV4, Cabo Frio, RJ" defendida pela autora em 2001 na FFLCH/USP. A revisão do artigo teve apoio da FAPERJ através do projeto "Soberanos da Costa".

(**) Departamento de Antropologia do Museu Nacional da Universidade Federal do Rio de Janeiro-UFRJ.

(1) Apesar de o termo ter sido utilizado desde o início do século como, por exemplo, por Speck (1926), um etnólogo pioneiro nos estudos da região Subártica Oriental, nos interessa o desenvolvimento do conceito na Antropologia Evolucionista que marcou os estudos sobre os grupos sambaquianos.
Devemos acrescentar que a Antropologia Social, embora desenvolvesse conceitos sobre sociedades primitivas frente aos novos dados etnográficos, exerceu também o papel de principal instrumento de manutenção do modelo teórico tradicional no que se refere às sociedades primitivas. Como analisa o autor, isso se deu porque, por um lado, a idéia de sociedade primitiva foi e é influenciada pela variedade de posições ideológicas existentes. Por outro, cada vez mais a idéia de sociedade primitiva era sustentada por forças internas relacionadas à própria afirmação da Antropologia enquanto ciência. H. Maine e seus contemporâneos estabeleceram sociedade primitiva como objeto da Antropologia Social. Assim, "sociedade primitiva começou a estruturar uma nova disciplina, que rapidamente desenvolveu um sofisticado conjunto quase matemático de técnicas de estudos de parentesco" (Kuper 1998:9). Tendo L. Morgan e E. Tylor como pioneiros, ${ }^{2}$ foi nos estudos de G. Murdock, F. Eggan, J. Steward e E. Service que essa questão adquiriu contornos mais sofisticados, pois contavam com melhores dados etnográficos que seus predecessores.

Tanto J. Steward quanto E. Service foram teóricos que basearam suas generalizações em antigos etnógrafos como, por exemplo, F. Boas e

(2) Esses dois estudiosos foram acompanhados por Bachofen, H.Maine, Fustel de Coulanges, J. Lubbock e R. MacLennan, todos compartilhando a idéia da sociedade primitiva, assumindo uma progressão direta dessas, através de vários estágios, para a sociedade moderna. 
V. Stefansson, mas foi na discussão sobre a natureza da sociedade primitiva, o caráter de bando marginal, que suas contribuições foram mais contundentes.

A premissa padrão foi apresentada por J. Steward em 1936 e ligeiramente aumentada em 1955 , sendo de E. Service a principal contraproposta em 1962. No primeiro trabalho, Steward (1936) estabeleceu três "tipos" de sociedades caçadorascoletoras quando observadas a partir do princípio de integração sociocultural: (1) o nível de integração familiar, (2) o nível de integração de bando e (3) um nível de integração caracterizado pelos clãs. A estruturação do modelo de bando parece ter sido baseada em dados etnohistóricos do século XIX sobre as Plain Indian Societes. Neste estudo estabelece, ainda, as categorias de bando identificadas como (a) bando linear (b) bando composto e (c) bando predatório.

A idéia de Steward tinha por base a cooperação entre os membros, a existência de uma chefia e a propriedade territorial. Contudo, os Shoshomi não pareciam demonstrar muita cooperação entre suas pequenas unidades sociais dispersas espacialmente, nem mantinham um chefe ou pareciam exercer direitos de propriedade sobre o território que exploravam. A resposta de Steward para a falta de correspondência entre sua definição de unidade social e a realidade estava relacionada a uma nova unidade, o nível de família de integração sociocultural, a qual tinha por base os estudos etnográficos junto às populações dos Grandes Lagos. $O$ reconhecimento posterior de Steward, de que o critério de tamanho incorporado em sua noção de bando era desencaminhado, o fez modificar sua visão à luz das pesquisas de campo mais detalhadas.

No segundo trabalho Steward (1955) propôs uma explicação demográfico-ecológica para a organização de bando, estabelecendo quatro fatores causais: baixa densidade da população, dependência da caça, transporte limitado e aceitação de tabus de incesto a todos os membros co-residentes de uma família extensa. Assim, o resultado é o que Steward denominou de "bando patrilinear", a mais difundida forma de organização social entre as sociedades marginais e a segunda mais simples (para reflexão sobre estudos de Steward ver Binford 2001).

Posteriormente, E. Service iria refutar três pontos das proposições de Steward: a não aceitação do domínio familiar como forma de organização social isolada, a refutação do bando composto como forma original de organização, visto ser um fenômeno produzido pelo contato, e o determinismo ecológico, que embora Steward tivesse evitado, fez uso de autores que sustentavam este pressuposto (Fried 1967).

A crítica de Service teve por base a revisão das estruturas de bando em escala mundial, definindo dois tipos: o primeiro, "um bando patrilinear é um grupo que é exogâmico e virilocal"; o segundo tipo é "o bando composto, um grupo onde faltam regras de exogamia e costumes explícitos de residência marital" (Service 1962:60). Sua crítica a Steward é mais profunda quando questiona o monolitismo de fatores demográficos para explicar organização social, pois considera que a organização social humana é cultural, sendo crucial a análise das estruturas e funções das associações e formas de agrupamentos sociais que atravessam localidades.

Nesse contexto, rapidamente a Antropologia incorporou, complementou e renovou o conceito de bando através, apenas para citar alguns, da concepção de reciprocidade de $\mathbf{M}$. Sahlins, este já um refinamento dos conceitos de K. Polany e de sociedades igualitárias simples, de $\mathbf{M}$. Fried. Somam-se a isso os três grandes encontros para discussões sobre o tema (Damas 1969, Lee e Devore 1968, Leacock e Lee 1982).

Em termos gerais, a concepção de reciprocidade proposta por Sahlins (1965) refere-se a um universo inteiro de trocas, um contínuo de formas, sendo caracterizada por dois pólos: assistência livremente oferecida e conseqüentemente generalizada, na qual a estipulação em aberto da retribuição seria impensada e anti-social, e a expropriação em proveito próprio, só compensável por um esforço igual e em sentido contrário.

Em trabalho publicado em 1967, M. Fried analisa as sociedades igualitárias simples com base nos traços gerais descritos na literatura etnográfica, detendo-se em alguns pontos discordantes como exogamia, tipologia de bandos e demografia. De acordo com o autor, a natureza das sociedades igualitárias simples abrange as seguintes características: dependência ao meio, o que as coloca numa posição de sociedades marginais; depopulação após o contato com o europeu, o que descaracterizou demograficamente a estrutura de bandos; acesso comunal indiferenciado aos recursos; divisão de trabalho por sexo; a não existência de grupos com 
atividades especializadas; a existência de partilha e de padrões de reciprocidade generalizada.

$\mathrm{O}$ autor se deterá mais na estrutura geral das sociedades igualitárias, visto serem o seu interesse as formas políticas que aí se desenvolveram. Assim, observa a existência de dois tipos de agrupamentos: um grupo menor, com uma forma familiar, geralmente nuclear e um agrupamento maior, o bando. Visto a família encontrar-se dentro de um contexto maior, o bando, ela não é tratada como uma unidade autônoma. Nesse sentido, concorda com Service (1962) e discorda de Steward (1955), sobre a existência de níveis de organização familiar. Fica clara sua concordância com os pressupostos de Service (1962), principalmente no que concerne à caracterização geral de bando. Contudo discorda da tipologia - matrilinear, patrilinear e composto pois considera uma frequiente presunção estabelecer que o caráter de um bando seja determinado pelo parentesco.

Assim, os modelos teóricos e os estudos etnográficos desenvolvidos junto aos caçadorescoletores deram início a conferências que os focalizavam, em termos gerais, e à concepção de bando, em particular. Três grandes encontros de discussões materializaram esta produção científica, dominando as décadas de 60 e 70: um primeiro, intitulado "Organização de Bandos", realizado pelo National Museum of Canada em 1965, e publicado sob a coordenação de D. Damas em 1968; um segundo, "Man, the Hunter", ocorrido na Universidade de Chicago, em 1966, tendo sido publicado em 1968 sob a coordenação de R. Lee e I. Devore, então membros do Harvard Kalahari Research Group; e a conferência sobre "Caçadores e Coletores", realizada na Maison des Sciences de l'Homme, em 1978, organizada por M. Godelier, sendo, posteriormente, editada por E.Leacock e R. Lee em 1982.

Enquanto o primeiro encontro centralizava as discussões em torno do conceito de bando, comparando sua natureza entre grupos forrageiros da Índia, América do Norte e África, discutindo similaridades e diferenças entre eles e demonstrando, assim, uma preocupação com a flexibilidade da estrutura de bando e a variabilidade de modelos de sazonalidade, o segundo caracterizou-se pela dinamização da produção etnográfica e, a partir dela, a observação da importância do papel feminino e, conseqüentemente, das atividades de coleta e pesca para as sociedades caçadoras.
Se no primeiro encontro iniciou-se o questionamento da universalidade e da rigidez do conceito de bando, no qual os trabalhos de Steward e Service citados anteriormente sofreram rápidas revisões críticas frente aos novos dados etnográficos, o segundo reforçou essa tendência, demonstrando a variabilidade e a particularidade da estrutura social de diferentes grupos denominados genericamente de "bandos", inaugurando ainda, também em resposta ao título "Man, The Hunter", estudos sobre gênero.

O último encontro, sob uma perspectiva materialista dialética, procurou recuperar o "core of features common" entre os grupos forrageiros, centrando as contradições nas particularidades de suas relações de produção. Foram abordadas também as relações entre esses grupos e a sociedade contemporânea e as consequiências do contato para aqueles.

Assim, a Antropologia e a Etnografia forneceram o aparato teórico sobre o qual se construiu o conceito de bando - de grandes generalizações a particularidades - permitindo verificar sua variabilidade estrutural dentro do sistema de caçadores-coletores, bem como seus pontos em comum.

No que concerne à Arqueologia, num primeiro instante, caberá tomar de empréstimo da Antropologia e dos estudos etnográficos a teoria socioevolucionista e o conceito de bando que ela encerra. Construído a partir do vetor temporal, conhecido comumente como uma escada evolutiva na qual, por ordem crescente, bando, tribo, cacicado e estado se sobrepõem no tempo e, também, com os auspícios de Leslie White e J. Steward (este último já descrito anteriormente), o neo-evolucionismo ganha corpo na Arqueologia, a partir da década de 50, através do advento da New Archaeology. Com suas "pretensões antropológicas e científicas", como observa Yoffee (1994:4), é rapidamente incorporado, como pode ser observado na afirmação de Sahlins (apud Yoffe 1994:5): “(...) qualquer representante de um dado estágio cultural é inerentemente tão bom quanto qualquer outro, seja o representante contemporâneo e etnográfico ou somente o arqueológico"

Isto será o suporte utilizado pela etnoarqueologia norte-americana, quando se iniciam estudos sobre organização social; desenvolvem-se à sombra dos estudos etnográficos e ganham autonomia ao assumir os "actualistics studies" 
Teórico da New Archaeology, agora denominada arqueologia processual, e representante mais reconhecido dos "actualist studies", L. Binford realizou estudos etnoarqueológicos junto a grupos de caçadores-coletores nos quais se reafirma a variabilidade proposta no encontro "Man, the Hunter" (Binford1978a; 1978b; 1980; 1982). Através da construção de modelos etnoarqueológicos de sistemas de assentamento e subsistência de grupos caçadores-coletores, estabelece o "foraging system" em oposição ao "colector system".

Esclarece que estes não são tipos polares, ao invés disso são graduações do simples ao complexo (Binford 1980). Recentemente (Binford 2001), reitera esta variabilidade em um amplo estudo sobre a construção da Teoria Arqueológica a partir de dados ambientais e etnográficos. ${ }^{3}$

Contudo, como afirmam Leacock e Lee (1982), populações forrageiras representam o mais próximo do que foi a condição original da humanidade, um sistema de produção que prevaleceu durante virtualmente noventa e nove por cento da história dos homens. Entretanto, é importante frisar que os "forrageiros" contemporâneos não são fósseis vivos que reproduzem literalmente os sistemas ancestrais da história da humanidade, pois como observou M. Sahlins, eles são "caçadores vivendo num mundo de não-caçadores", estando inseridos no contexto do século XX. Assim, a pesquisa arqueológica de grupos pré-históricos tem muito a acrescentar sobre a organização social, sendo de importância fundamental tanto no que concerne à complementação quanto à refutação dos modelos etnográficos e/ou etnoarqueológicos, evolucionistas ou não.

Como observa Yoffe (1994:10), o modelo evolucionista "amarrava todas as instituições em um pacote, no qual mudanças tinham que ocorrer em todas as instituições ao mesmo tempo, no mesmo ritmo e na mesma direção" O autor afirma que na visão neo-evolucionista, a teoria de sistemas abarcava o substantivismo: um tipo particular de

(3) Neste estudo, ao realizar uma releitura dos estudos etnográficos sobre caçadores e coletores, o autor propõe, ainda, um pragmatismo maior na abordagem das unidades conceituais e de análise da pesquisa etnoarqueológica, pois observa que as unidades de observação do pesquisador necessitam de constante redefinição no sentido de acomodar a variabilidade que é seqüencialmente encoberta pelo mundo dinâmico. economia era encaixado num tipo de sociedade correspondente. Assim, bando e tribo caracterizavam-se por reciprocidade, enquanto cacicado pela redistribuição.

Muitos se juntam a N. Yoffe na crítica a este modelo, como Bawden (1989), Feinman e Neitzel (1984), Mcguire (1983) e Paynter (1989), todos recusando a tipologia neo-evolucionista por suas características atávicas, holísticas e transformacionais de mudança social.

Apesar da vasta produção etnoarqueológica e das críticas ao neo-evolucionismo, discorrendo, no primeiro caso, sobre a variabilidade das formas que a estrutura de bando adquire em cada um dos grupos analisados e, no segundo caso, dos limites do uso de estágios culturais, apenas o trabalho posterior de Service, em 1966, e o trabalho citado de Steward (1955), influenciaram, no Brasil, os estudos sobre organização social dos grupos pescadores-coletores (construtores de sambaquis). Ambos tornaram-se "bíblias antropológicas", ainda que raramente citados.

A publicação de Service Os Caçadores nada mais é do que uma reafirmação bastante condensada de sua publicação anterior, caracterizando-se como uma tentativa de descrever resumidamente, no melhor estilo evolucionista, os grupos caçadorescoletores a partir de um amplo e heterogêneo referencial bibliográfico, compreendendo desde estudos etnográficos e etnohistóricos que datam do enclave planetário indo até às pesquisas etnográficas da década de 60. Mesmo assim forneceu, juntamente com o trabalho de Steward (1955), subsídios para caracterizar a estrutura de bando dos grupos sambaquianos.

O simples uso de palavra bando, microbando e/ou macrobando, estes últimos em menor freqüência, associado a duas características, as atividades de subsistência (coleta de moluscos e pesca) e a mobilidade (nomadismo), ambos como reflexo direto das mudanças e imposições ambientais, explicou a organização social dos sambaquianos durante décadas (Uchôa 1973; Kneip 1987; Dias 1992; Dias e Carvalho 1995; Mendonça de Souza 1995, apenas para citar alguns). Manteve-se, de forma sutil, visto não existirem pesquisas que abordassem diretamente esta questão, o binômio espacial nomadismo/ambiente, sustentáculo do conceito generalizador proposto por Service e que tinha por características o baixo índice demográfico e tecnológico, uma fragilidade integradora (obtida 
apenas através das concepções de parentesco) e a concepção de família como o único grupo estável e estruturador da organização social e cultural.

Dentro desta perspectiva, Dias e Carvalho (1995) reafirmam a organização social sambaquiana a partir do estabelecimento de um grupo que se distingue dos bandos nômades ("fase Macaé"), a "fase Corondó". Caracterizando-o como macrobando, os autores analisam a longa permanência dessa organização através do isolamento social imposto pela compartimentação ambiental, ou seja, fatores de restrição ecológica determinaram, em primeira instância, a estrutura social dos grupos pertencentes à "fase Corondó" Em trabalhos anteriores (Dias e Carvalho 1983; Machado 1984), a organização de macrobando da "fase Corondó", então denominada de fase "Itaipu B", era explicada através da alta densidade demográfica, da freqüência de cáries e da existência de uma agricultura incipiente.

Raras publicações sobrepuseram-se ao paradigma evolucionista e ecológico, sendo pioneiro o trabalho de Gaspar (1991) que contesta a generalização da terminologia de bando, apesar de considerar que os grupos sambaquianos compartilham das características gerais propostas por Leacock e Lee (1968). Existe, ainda, o trabalho de Lima (1995), para o contexto insular, e que se aproxima das proposições de Gaspar (1991).

Assim, a organização social dos construtores de sambaquis, materializada na estrutura de bando, forneceu um modelo no qual o espaço foi traduzido em dois pólos extremos, a mobilidade constante (acampamentos sazonais/bandos) e a longa permanência (aldeias sedentárias / macrobandos). Contudo, quase nada se acrescentou a essa definição generalizadora de bando, não somente na caracterização de sua estrutura, mas também na sua dinâmica espacial, embora esta última tenha tido maiores e melhores contribuições (Barreto 1988; Gaspar 1991).

A questão da dinâmica espacial dos grupos construtores de sambaquis, a qual os estudos etnoarqueológicos denominam de "estratégia de mobilidade", numa clara acepção econômica, deve ser abordada, primeiramente, sob o ponto de vista conceitual. Nomadismo, seminomadismo, semisedentarismo e sedentarismo, termos utilizados comumente para designar a mobilidade, notadamente para os grupos caçadores-coletores atuais, devem ser reconceitualizados quando se tem como referenciais grupos pré-históricos, notadamente grupos pescadores-coletores.

Essa reconceitualização torna-se necessária tendo em vista que esses conceitos foram forjados em oposição ao modo de vida sedentária, característico às sociedades urbanas neolíticas. Assim é que Sahlins afirma que "a tendência da Antropologia a exagerar a ineficácia econômica dos caçadores manifesta-se notadamente por comparações não obrigatórias com a economia neolítica" (Sahlins 1972:42).

A manutenção da concepção de sedentarismo, a grosso modo, como um modo de vida restrito a grupos que ocupam o mesmo sítio por muito tempo (anos), aparentemente não possui paralelo com o passado. Excetuando locais urbanos e áreas de alta densidade populacional, a ocupação de um mesmo local por muitas gerações foi provavelmente um raro fenômeno na pré-história.

$\mathrm{Na}$ antropologia evolucionista, o nômade foi durante muito tempo entendido como aquele que passa todos os momentos de sua vida fugindo da fome ou, numa visão menos "pessimista", se é que se pode entender assim, aquele que vive atrás da comida, como um oposto ao sedentário. Contudo, a relação nômade/sedentário é menos dicotômica do que aparenta, "trata-se antes de uma relação de complementaridade do que de oposição, marcada não obstante pela diferença: um termo é irredutível ao outro, inclusive conceitualmente. Não chegaremos ao nômade pela mera oposição ao sedentário: ele é outro, mais do que o seu negativo" (Marques et al. 1999:22).

Assim, a Arqueologia deve forjar esses conceitos - bando, macrobando, nômade, sedentário - a partir da produção dos seus dados empíricos, o que necessariamente não elimina o uso de modelos etnoarqueológicos.

Entre sedentarismo e nomadismo são muitas as nuanças e chegam mesmo a falar em "hipersedentarismo" ou "supra-sedentarismo" quando se abandona o valor absoluto de tempo, relativizando-o a partir dos grupos focalizados.

Talvez o problema de se abordar a estrutura social dos grupos sambaquianos seja exatamente o de desconsiderar que tempo e espaço são socialmente dados, sendo somente permitido compreendê-los a partir do contexto sistêmico onde foram produzidos. A questão não é recuperar o passado a partir somente de testemunhos arqueológicos que sejam próprios a uma determinada sociedade, visto 
considerarmos o passado uma construção da arqueologia, mas sim estimular o processo de seleção conceitual, inserindo, descartando e/ou realocando novas e antigas formulações.

Steward foi o pioneiro na investigação das relações ecológicas que os caçadores-coletores mantinham com seu ambiente, e sua pesquisa neste domínio constituiu sua mais importante herança. As pesquisas de Speck, Leacock, Lee e Steward apontaram para o interesse no padrão atual da organização social dos caçadores-coletores observando que as vias tradicionais de interpretação do passado não podem explicá-lo. Como observa Binford (2001:22) muitos elementos de Sahlins são ainda relevantes - particularmente aqueles relacionados à distribuição e à união para a produção de recursos como formas fundamentais de cooperação - mas esses elementos são agora incorporados em algumas novas e interessantes perspectivas.

\section{Referências bibliográficas}

\section{BAWDEN, G.}

1989 The Andean state as a state of mind. Journal of Anthropological Research, 45: 327-332.

\section{BARRETO, C.N.G.B}

1988 Ocupação do vale do Ribeira do Iguape, São Paulo: os sítios concheiros do médio curso. Dissertação de Mestrado. São Paulo: Faculdade de Filosofia, Letras e Ciências Humanas, Universidade de São Paulo.

\section{BEZERRADE MENESES, U.T}

1983 A cultura material no estudo das sociedades antigas. Revista de História, (Nova Série), 115, São Paulo: 103-117.

BINFORD,L.

1978a Introduction to Nunamiut Ethnoarchaeology. New York: Academic Press.

1978b Dimensional analysis of Behavior and site structure: Learning from Eskimo Hunting Stand. American Antiquity, 43: 330-361.

1980 Willow Smoke and Dogs' Tails: Huntergatherer settlement /systems and archaeological site formation. American Antiquity, 45 (1): 4-20.

1982 Archaeology of Place. Journal o Anthropological Archaeology, 1 (1): 5-31.

2001 Constructing Frames of Reference. Berkeley: University of California Press.

DAMAS, D.

1969 Contributions to Anthropology: Band Societies. National Museum of Canada. Canadá: Bulletin, 228.

DIAS JÚNIOR, O.F.

1992 A tradição Itaipu, costa central do Brasil. B. Meggers (Ed.) Prehistoria Sudamericana Nuevas Perspectivas. Washington, Taraxacum: 161-176.

DIAS, O.; CARVALHO, E.

1983 Um possível foco de domesticação de plantas no Estado do Rio de Janeiro/RJ-JC-64 (sítio Corondó). Boletim do IAB, Série Ensaios, Rio de Janeiro: 1 (1): 1-18.

1992 A tradição Itaipu no Rio de Janeiro: Discussão dos tópicos: a questão da imobilidade cultural. M.C. Beltrão (Org.) Arqueologia do Estado do Rio de Janeiro. Rio de Janeiro: Arquivo Público do Estado do Rio de Janeiro: 105-110.

FEINMAN, K.; NEITZEL, J.

1983 Too many types: an overview of sedentary prestate societies in the Americas. Advances in Archaeological Method and Theory, 7: 39-102.

FRIED, $M$.

1967 A Evolução da Sociedade Política. Rio de Janeiro: Zahar.

KNEIP, L.M.

1987 Coletores e Pescadores Pré-Históricos de Guaratiba, Rio Janeiro. Rio de Janeiro: Série Livro, 5, EDUFF/UFRJ, Museu Nacional.

GASPAR, M.D.

1991 Aspectos da Organização de um Grupo de Pescadores, Coletores e Caçadores: Região Compreendida entre a Ilha Grande e o Delta do Paraíba do Sul, Estado do Rio de Janeiro. Tese de Doutorado. São Paulo, Faculdade de Filosofia, Letras e Ciências Humanas, Universidade de São Paulo.

KUPER,A.

1988 The Invention of Primitive Society. London: Routledge.

1982 Politics on History In Band Societies. Cambridge: Cambridge University Press.

LEE, R.; DEVORE, W.

1968 Man, The Hunter. Cambridge: Cambridge University Press.

LIMA, T.A.

1995 Ocupações pré-históricas em ilhas do Rio de Janeiro. M.C. Beltrão (Org.) Arqueologia do Estado do Rio de Janeiro. Rio de Janeiro: Arquivo Público do Estado do Rio de Janeiro: 95-104.

MACHADO, L.C.

1984 Análise dos Remanescentes Ósseos Humanos do Sítio Arqueológico Corondó, RJ. Aspectos Biológicos e Culturais. Tese de Doutorado. São Paulo: Faculdade de 
Filosofia, Letras e Ciências Humanas, Universidade de São Paulo.

MARQUES, A.C.; BROGNOLI, F.F.; VILELA, J.L.M.

1999 Andarilhos e cangaceiros: a arte de produzir território em movimento. Itajaí: Ed. Universidade do Vale do Itajaí.

\section{MCGUIRE, $R$.}

1983 Breaking down cultural complexity: inequality and heterogeneity. Advances in Archaeological Method and Theory, 6: 91-142.

MENDONÇADE SOUZA, A.

1995 Povoamento Pré-Histórico do Litoral do Rio de Janeiro. repensando um modelo. M.C. Beltrão (Org.) Arqueologia do Estado do Rio de Janeiro. Rio de Janeiro: Arquivo Público do Estado do Rio de Janeiro: 69-78.

PAYNTER, $R$.

1989 The archaeology of equality and inequality. Annual Review of Anthropology, 18: 369-399.

\section{SAHLINS, $M$.}

1965 On the Sociology of Primitive Exchange. M. Banton The Relevance of Models for Social Anthropology. New York: Association for Social Anthropologist Monograph 1.

1972 Stone Age Economics. New York: Aldine de Gruyter.

\author{
SERVICE,E. \\ 1962 Primitive Social Organization: An Evolutionary \\ Perspective. New York: Random House. \\ 1966 Os Caçadores. Rio de Janeiro: Zahar. \\ SPECK, F.G \\ 1926 Culture problems in Northeastern North \\ America. Proceedings of the American \\ Philosophical Society, 65, n.4. \\ STEWARD, J. \\ 1936 The economy and social basis of primitive \\ bans. R.H. Lowie (Ed.) Essays in Anthropology \\ Presented to Alfred Louis Kroeber. Berkeley, \\ University of California Press: 331-350. \\ 1955 The Theory of Culture Change. Urbana: \\ University of Illinois Press. \\ UCHÔA, D.P. \\ 1973 Arqueologia de Piaçaguera e Tenório: análise \\ de dois sítios pré-cerâmicos do litoral \\ paulista. Tese de Doutoramento, Faculdade \\ de Filosofia, Ciências e Letras de Rio Claro. \\ YOFFEE, $\mathrm{N}$. \\ 1994 Cacique demais? (ou textos seguros para os \\ anos 90). P. Fish; E.J. Morley (Eds.) II Workshop \\ de Métodos Arqueológicos e Gerenciamento \\ de Bens Culturais. 11 ${ }^{\mathrm{a}}$ Coordenadoria \\ Regional do IPHAN, Florianópolis.
}

